\title{
A rare cause of meningitis whilst on anti-IL6 therapy
}

James Wingfield-Digby MBChB MRCP, SpR Respiratory Medicine, Wythenshawe Hospital (1st Author), Saffwan Mohammed MBChB, ST1 Neurosurgery, Royal Preston Hospital, Henry HL Wu MBChB, Academic FY2, Royal Lancaster Infirmary

\section{PRESENTATION}

An 80 year old lady presented to the emergency department with acute drowsiness and confusion. She had a 3 day history of coryzal symptoms and diarrhoea prior to admission. On admission the patient was responsive to pain only so further history was not possible.

She had a background of seropositive and anti-CCP positive rheumatoid arthritis. She also had bronchiectasis and rheumatoid related pulmonary nodules. She had chronic scleritis, osteoporosis, and recent episode of trigeminal nerve shingles. She was taking Vitamin D replacement.

She had been on Tocilizumab a monoclonal antibody against IL-6 since 2015 having previously been on different anti-TNF medication. She had also been on
Denosumab for osteoporosis since 2016. She had been taking maintenance Prednisolone since the age of 40; with a dose of $5 \mathrm{mg}$ once daily on admission.

On examination she was drowsy with a GCS of E2M6V3 - 11/15 and dehydrated. She had bibasal crepitations and a respiratory rate 34 . She had a pansystolic murmur at the apex but no splinter haemorrhages. Her JVP was not elevated. Her abdomen was soft. Pupils were $5 \mathrm{~mm}$ bilaterally and equally responsive to light. She was not able to follow commands but no facial asymmetry was noted. Her plantars were downgoing with no increased tone or hyperreflexia.

INITIAL INVESTIGATIONS (TABLE 1-3)

Table 1

\begin{tabular}{|l|l|l|l|}
\hline Test & Results & Units & Ref range \\
\hline SODIUM & 144 & $\mathrm{mmol} / \mathrm{L}$ & 133 to 146 \\
\hline POTASSIUM & 3.7 & $\mathrm{mmol} / \mathrm{L}$ & 3.5 to 5.3 \\
\hline UREA & 9.5 & $\mathrm{mmol} / \mathrm{L}$ & 2.5 to 7.8 \\
\hline CREATININE & 67 & $\mathrm{umol} / \mathrm{L}$ & 60 to 110 \\
\hline eGFR & 73 & $\mathrm{~mL} / \mathrm{min} / 1.73 \mathrm{~m}^{2}$ & \\
\hline BILIRUBIN & 33 & $\mathrm{umol} / \mathrm{L}$ & 0 to 21 \\
\hline ALANINE TRANSAMINASE & 32 & $\mathrm{U} / \mathrm{L}$ & 0 to 40 \\
\hline ALKALINE PHOSPHATASE & 54 & $\mathrm{U} / \mathrm{L}$ & 30 to 130 \\
\hline ALBUMIN & 40 & $\mathrm{~g} / \mathrm{L}$ & 35 to 50 \\
\hline C REACTIVE PROTEIN & $<4$ & $\mathrm{mg} / \mathrm{L}$ & 0.0 to 10.0 \\
\hline
\end{tabular}

Table 2

\begin{tabular}{|l|l|l|l|}
\hline Test & Results & Units & Ref range \\
\hline HB & 145 & g/L & 120 to 160 \\
\hline WBC & 21.5 & $10^{\wedge} 9 / \mathrm{L}$ & 4.0 to 11.0 \\
\hline PLATELET & 155 & $10^{\wedge} 9 / \mathrm{L}$ & 150 to 450 \\
\hline MCV & 98.9 & $\mathrm{Fl}$ & 78 to 97 \\
\hline NEUTROPHIL & 20.0 & $10^{\wedge} 9 / \mathrm{L}$ & 1.7 to 8.0 \\
\hline LYMPHOCYTE & 0.8 & $10^{\wedge} 9 / \mathrm{L}$ & 1.0 to 4.0 \\
\hline MONOCYTE & 0.4 & $10^{\wedge} 9 / \mathrm{L}$ & 0.24 to 1.1 \\
\hline EOSINOPHIL & 0.1 & $10^{\wedge} 9 / \mathrm{L}$ & 0.1 to 0.8 \\
\hline BASOPHIL & 0.1 & $10^{\wedge} 9 / \mathrm{L}$ & 0.0 to 0.3 \\
\hline HCT & 0.43 & $\%$ & 0.37 to 0.47 \\
\hline INR & 0.9 & Ratio & 0.8 to 1.1 \\
\hline
\end{tabular}

Table 3

\begin{tabular}{|l|l|l|l|}
\hline $\begin{array}{l}\text { Test - Arterial } \\
\text { blood gas on air }\end{array}$ & Results & Units & Ref range \\
\hline $\mathrm{pH}$ & 7.44 & & $7.35-7.45$ \\
\hline $\mathrm{PO} 2$ & 6.3 & $\mathrm{kPa}$ & $11-14.4$ \\
\hline $\mathrm{PCO} 2$ & 3.7 & $\mathrm{kPa}$ & $4.7-6$ \\
\hline Lactate & 5.3 & $\mathrm{mmol} / \mathrm{L}$ & $<1.6$ \\
\hline $\mathrm{HCO} 3$ & 18.5 & $\mathrm{mmol} / \mathrm{L}$ & $22-26$ \\
\hline
\end{tabular}




\section{IMAGING}

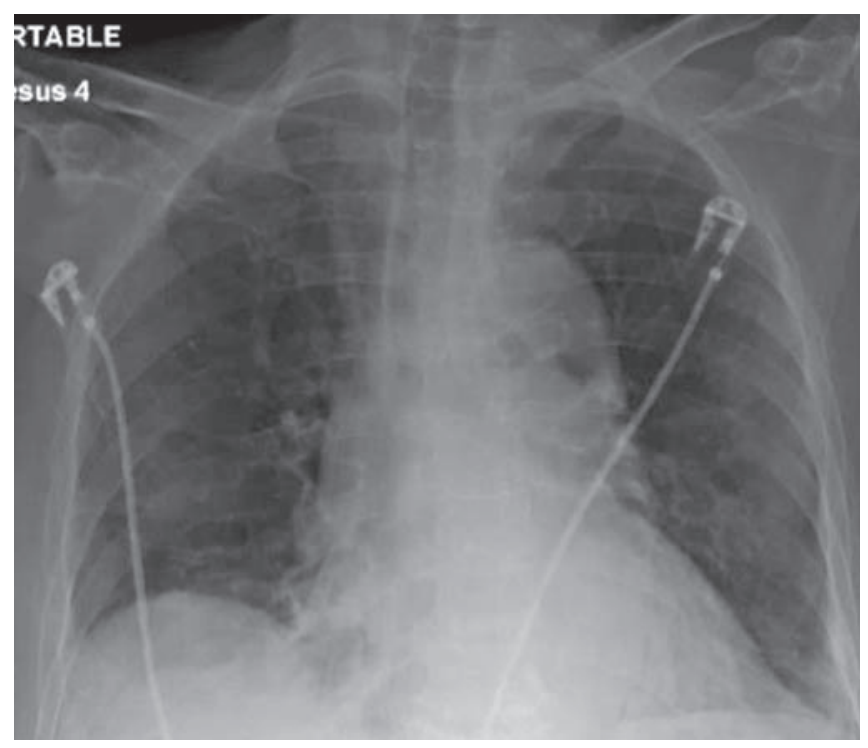

Figure 1: No major collapse or consolidation

\section{INITIAL MANAGEMENT AND FURTHER INVESTIGATION}

The impression was that she had a lower respiratory tract infection and septicaemia. It was also felt that treatment to cover a CNS infection should be started with a view to performing a lumbar puncture (Table 4).

\section{Table 4}

\begin{tabular}{|l|l|l|l|}
\hline Test & Results & Units & Ref range \\
\hline Cell count & \multicolumn{1}{|l|}{ Bloodstained, WBC 1780, RBCs $15480,(\mathrm{per} / \mathrm{ul})$} \\
\hline WBC breakdown & $100 \%$ polymorphs \\
\hline CSF protein & 4.74 & $\mathrm{~g} / \mathrm{L}$ & $0.08-0.32$ \\
\hline CSF lactate & 17.6 & $\mathrm{mmol} / \mathrm{L}$ & $1.1-2.4$ \\
\hline CSF glucose & 0.8 & $\mathrm{mmol} / \mathrm{L}$ & \\
\hline
\end{tabular}

\section{DIFFERENTIAL DIAGNOSIS AND FURTHER INVESTIGATION}

Table 5

\begin{tabular}{|l|l|}
\hline \multicolumn{2}{|l|}{ Differential diagnosis for meningitis in patient on TNF therapy } \\
\hline Bacterial Meningitis & Viral Meningitis \\
\hline TB Meningitis & Toxoplasmosis \\
\hline Cryptococcal Meningitis & Neurosyphilis \\
\hline
\end{tabular}

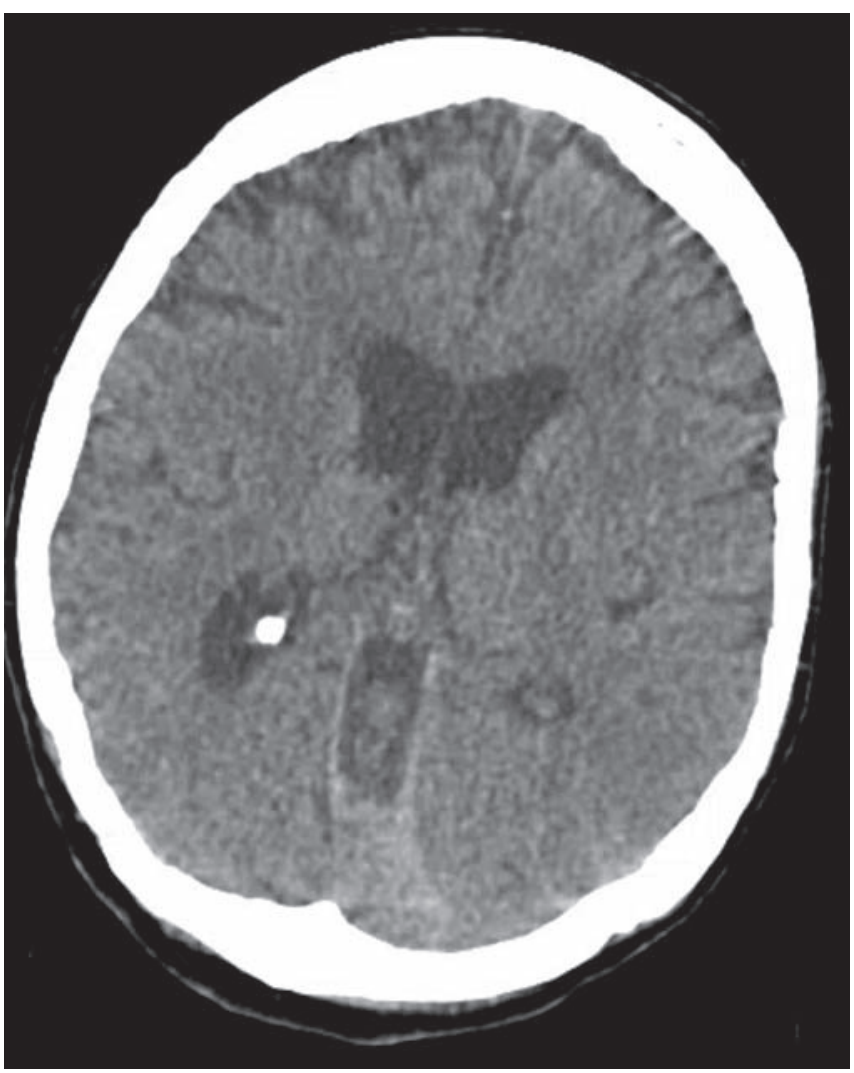

Figure 2: Loss of grey-white matter differentiation. Right paracentral chronic infarct. Otherwise unremarkable appearances

\section{MANAGEMENT}

The patient was admitted to Medical High Dependency Unit (MHDU). She was started on Meropenem $2 \mathrm{~g}$ TDS and Aciclovir. A lumbar puncture was performed and the initial results are shown below. Given the significantly raised WCC count and CRP a CT abdomen and pelvis was performed to look for deep seated infection (Figure 3 shown on next page).

Her GCS remained 11/15 and EEG was performed alongside a transthoracic echocardiogram to look for evidence of vegetation's suggestive of endocarditis.

The case was discussed with the local infectious diseases centre who advised additional serology tests as outlined below and further lumbar puncture with extra CSF for TB culture. The results of these are shown (Table 6). 
Table 6

\begin{tabular}{|l|}
\hline Test \\
\hline Serum Toxoplasma IgG antibody NOT detected \\
\hline Serum HTLV $1 / 2$ antibody NOT detected \\
\hline Serum HIV-1/HIV-2 antibody and P24 antigen NOT detected \\
\hline Treponemal antibody NOT detected. \\
\hline CSF AFB not seen. Liquid culture for Mycobacteria NEGATIVE at 6 weeks \\
\hline CSF BK virus DNA NOT detected by PCR (less than 50 copies/ml) \\
\hline CSF JC virus NOT detected by PCR (less than 50 copies/ml) \\
\hline CSF EBV,CMV, VZV, EBV, Enterovirus : PCRs all negative \\
\hline
\end{tabular}

Electroencephalogram (EEG): showed slowing of the background rhythm dominated by mixed frequency slowing in keeping with triphasic wave encephalopathy. Pattern was non-specific to aetiology and can be seen in a variety of inflammatory/ infective encephalopathies. There is no evidence of ongoing non-convulsive status epilepticus on the EEG (Figure 3).

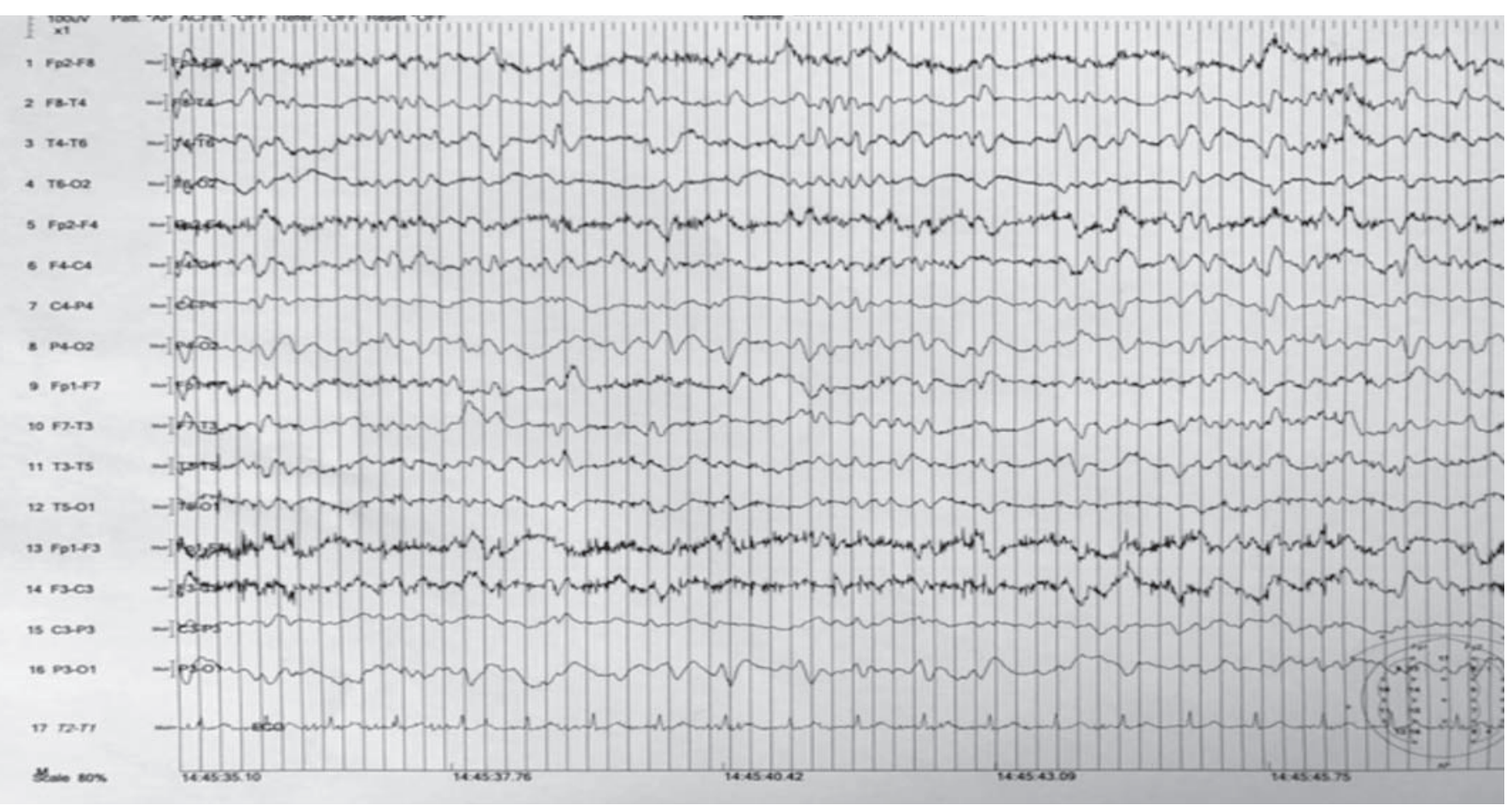

Figure 3: EEG

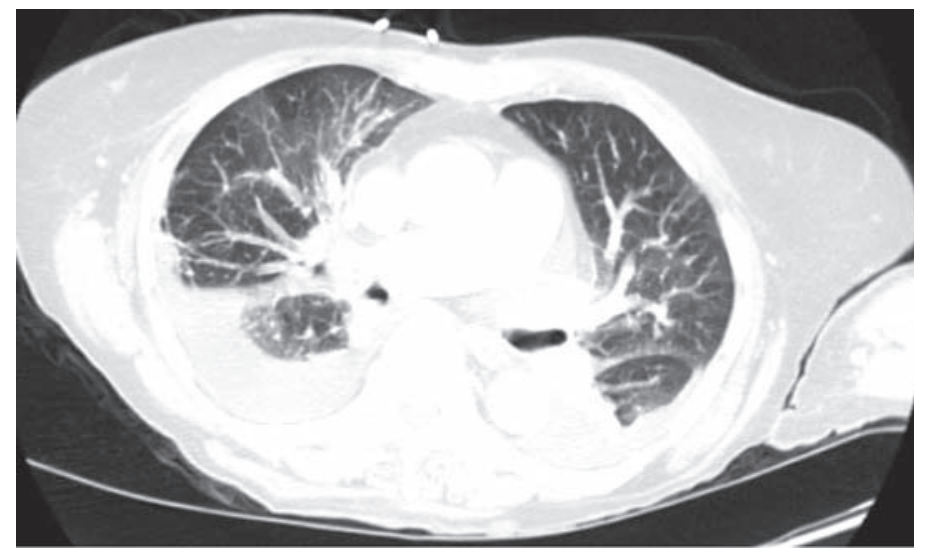

Figure 4: CT TAP. Small to moderate bilateral pleural effusions. Otherwise unremarkable 


\section{FURTHER INVESTIGATIONS}

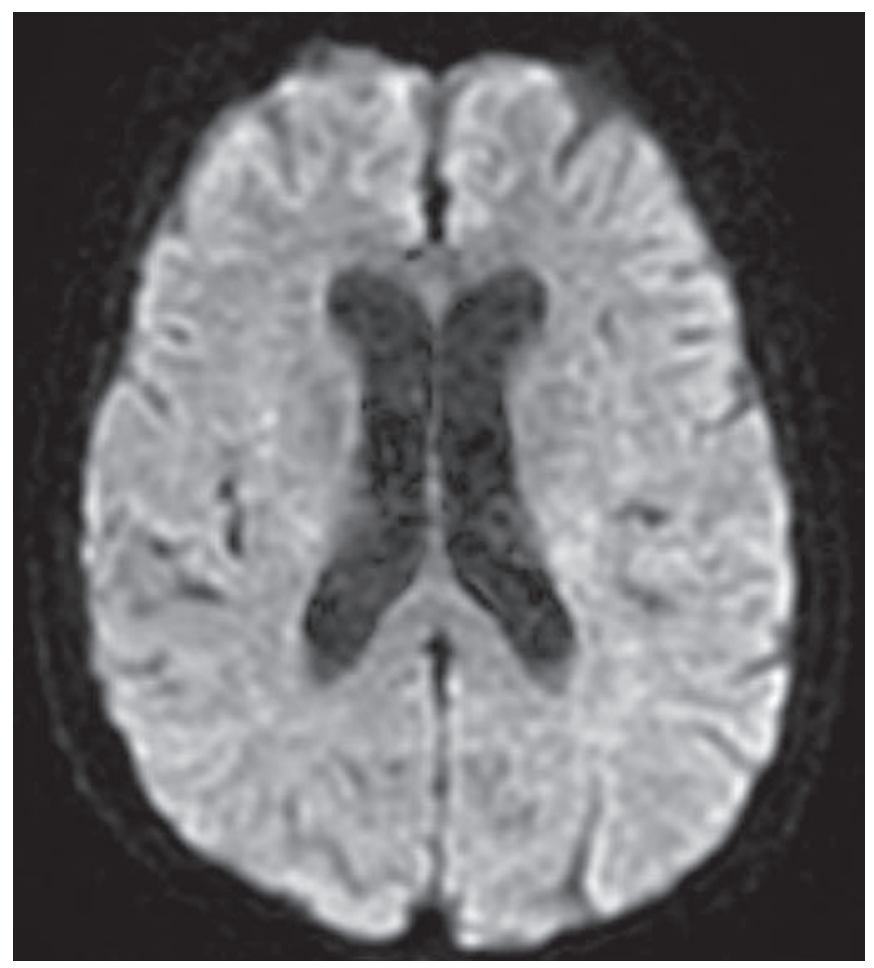

Figure 5: MRI Brain. Diffuse weighted imaging (DWI) showed high signal in the dependent part of both lateral ventricles in keeping with purulent material

\section{OUTCOMES AND TREATMENT}

\section{CSF bacterial culture}

Gram result:Gram negative bacilli +/-.

Appearance: CSF bloodstained + turbid

$\begin{array}{lc}\text { WBC count (per ul): } 6520 & \text { Polymorphs: 100\% } \\ \text { RBC count (per ul): 5360 } & \text { Lymphocytes: 0\% } \\ & \\ \begin{array}{l}\text { Organism: } \\ \text { 1. Citrobacter koseri }\end{array} & \text { Quantity } \\ \end{array}$

Gentamicin S

Meropenem S

\section{OUTCOME}

She was stepped down to a medical ward and made a slow but good neurological recovery. She became less drowsy and more orientated. She completed a 3 week course of IV meropenem. She received physio on the ward and re-established her baseline which was walking with a stick. She was discharged home on a maintenance dose of prednisolone and was going to be followed up by her rheumatology team.

\section{DISCUSSION}

Citrobacter species are gram negative non-sporing forming bacilli. They form part of the normal human digestive tract flora and can be further divided into
C. amalonaticus, C. freundi and C. koseri. Citrobacter koseri, formerly known as Citrobacter diversus, is a rare cause of neonatal meningitis; usually in premature immunocompromised infants. ${ }^{1}$ In neonates, the infection is often fulminant resulting in intracerebral abscess formation in $75 \%$ and complications include septicaemia, empyema and ventriculitis. Unfortunately, mortality remains high at 30\% and there is $50 \%$ chance of severe neurological impairment in survivors. ${ }^{2}$ Our literature review revealed very few cases of Citrobacter koseri in the adult population. There were six patients identified with Citrobacter meningitis from 1966 to 1994. ${ }^{3-9}$ Of this small cohort of cases, three had undergone recent neurosurgical intervention and one presented with facial fractures. ${ }^{3-9}$ It is even rarer in the absence of recent neurosurgical intervention. This patient's treatment with an IL-6 inhibitor and long term prednisolone may have contributed to this risk.

The use of biological Disease Modifying Anti Rheumatoid Drugs (bDMARDS) to treat severe rheumatoid arthritis (RA) has expanded over the last decade. $^{10}$ Tocilizumab is an IL-6 inhibitor that has shown promising results in treating severe RA compared to traditional DMARDs such as methotrexate. ${ }^{11}$ Trials have shown that the rate of adverse events such as serious infections is generally similar to the traditional DMARDs, with 4.7 events per 100 patient-years. ${ }^{12}$ However, this is slightly higher when Tocilizumab is used in combination with DMARDs or corticosteroids. ${ }^{12}$ Most common infections included pneumonia, urinary tract infections, cellulitis, herpes zoster, diverticulitis, sepsis and bacterial arthritis. Opportunistic infections such as tuberculosis, Cryptococcus, aspergillosis, candidiasis, and pneumocystis have also been reported. Other serious opportunistic infections that may be associated with Tocilizimab include histoplasmosis, coccidioidomycosis and listeriosis, although none has been reported in clinical studies. ${ }^{10-12}$

We hypothesised that our patients' pre-existing immunosuppression from prolonged corticosteroid use and her treatment with an IL-6 inhibitor resulted in increased susceptibility. Early blood cultures and cerebrospinal fluid culture aided us in making the diagnosis and planning a prolonged treatment course. Our treatment was guided by our local microbiology team and despite the severity of her infection and evidence of ventriculitis on her MRI she seemed to have little neurological sequelae or impairment on discharge.

We recommend considering Citrobacter species as an unusual cause of CNS infection in patients with preexisting immunosuppression. In the absence of other causes diabetes mellitus appears to be a risk factor in cases we identified.

\section{REFERENCES}

1. Etuwewe O, Kulshrestha R, Sangra M et al. Brain abscesses due to Citrobacter koseri in a pair of twins. The Pediatric Infectious Disease Journal. 2009;28(11):1035.

2. Kariholu U, Rawal J, Namnyak S. Neonatal Citrobacter koseri meningitis and brain abscess. Internet J Pediatr Neonatol. 2009;10:1.

3. Berk SL, McCabe WR. Meningitis caused by gram-negative bacilli. Annals of Internal Medicine. 1980;93(2):253-60.

4. Lok-Ming T, Sien-Tsong C, Tai-Ngar L. Citrobacter meningitis in adults. Clinical Neurology and Neurosurgery. 199496(1):52-7. 
5. Scheld WM, Tyson GW. Citrobacter freundii meningitis in an adult. Southern Medical Journal. 1979;72(12):1598.

6. Madrazo A, Geiger J, Lauter CB. Citrobacter diversus at Grace Hospital, Detroit, Michigan. The American Journal of the Medical Sciences. 1975;270(3):497-501.

7. Lin SY, Ho MW, Yang YF et al. Abscess caused by Citrobacter koseri infection: three case reports and a literature review. Internal Medicine. 2011;50(12):1333-7.

8. Booth LV, Palmer JD, Pateman J et al. Citrobacter diversus ventriculitis and brain abscesses in an adult. Journal of Infection. 1993;26(2):207-9.

9. Lind CR, Muthiah K, Bok AP. Peritumoral Citrobacter koseri abscess associated with parasagittal meningioma. Neurosurgery. 2005;57(4):E814-.

10. Smolen JS, Landewé R, Bijlsma J et al. EULAR recommendations for the management of rheumatoid arthritis with synthetic and biological disease-modifying antirheumatic drugs: 2016 update. Annals of the rheumatic diseases. 2017;76(6):960-77.
11. Jones G, Sebba A, Gu J et al. Comparison of tocilizumab monotherapy versus methotrexate monotherapy in patients with moderate to severe rheumatoid arthritis: the AMBITION study. Annals of the Rheumatic Diseases. 2010;69(01):88-96.

12. Nishimoto N, Miyasaka N, Yamamoto K. et al. Study of active controlled tocilizumab monotherapy for rheumatoid arthritis patients with an inadequate response to methotrexate (SATORI): significant reduction in disease activity and serum vascular endothelial growth factor by IL-6 receptor inhibition therapy. Modern Rheumatology. 2009;19(1):12-9.

Correspondence to: jxw640@gmail.com

James Wingfield-Digby MBChB MRCP, SpR Respiratory Medicine, Wythenshawe Hospital

\section{The 2018 Sir Richard Owen Lecture}

\section{Francis Wells and The Heart of Leonardo by Bryan Rhodes}

'How could you describe this heart without filling a whole book' - Leonardo da Vinci c. 1513

Wednesday October 17 th was the date for this year's lecture, the first to take place mid-week due to $\mathrm{Mr}$. Wells' commitments in the operating theatre. Consultant cardiothoracic surgeon at Papworth since 1986 and widely regarded as one of the world's leading cardiac surgeons, our speaker also has a passion for the history of anatomy that really illuminated a fabulous lecture.

Filled with anecdotes (did you know Samuel Pepys had designed the first bookshelf?) and insight and detail, the lecture also highlighted the research $\mathrm{Mr}$ Wells had performed to confirm Leonardo's original theories on cardiac function. Although, Leonardo only completed a small number of paintings and sculptures he was prolific in his scientific research into subjects such as hydrodynamics, optics and human anatomy. Fortunately, the bulk of his anatomical sketches

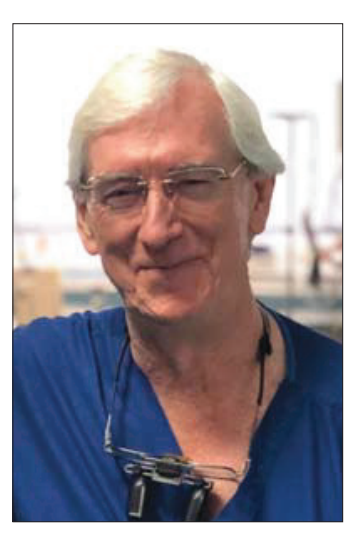
survive and reside in the Queen's collection at Windsor. Many of these feature the famous mirror writing used by Leonardo. Mr Wells explained that $10 \%$ of left handed people had the ability to write easily in mirror mode so this may not have been an attempt to hide his discoveries.

$\mathrm{Mr}$ Wells outlined the 3 periods of Leonardo's anatomical research. Firstly, in the late 1480's/early 1490's when he lived in Milan and he includes a number of Galenic principles. Secondly, in the period from 1507 to 1511 which included his last year in Florence and his return to Milan and Paris. One of the intriguing events of this period is his dissection of an old man of over a 100 years of age at the hospital of Santa Maria Nuova in Florence. Leonardo speaks to him 'a few hours before his death' and then dissects him soon afterwards. Leonardo identifies coronary atherosclerosis, suggests this is the cause of death and also concludes that the heart and not the liver is the central organ of the circulatory system. This period should have been the culmination of his anatomical work but the death (due to bubonic plague) of anatomist and collaborator Marcantonio Della Torre scuppers plans for an anatomical textbook for artists and Leonardo moves to Rome in 1513 . Here in $1514 / 15$ he completes his final anatomical studies but experiences further frustration: a German (ironically a mirror maker ) denounces his work to the Pope and he is 'hindered' in his research.

Leonardo substituted ox hearts to continue his research on the heart and in one respect this was helpful - the aortic sinuses of Valsalva are more pronounced in the ox and Leonardo used his knowledge of vortices to identify the mechanism of closure of the aortic valve. Using video technology Mr Wells showed how Leonardo had been correct.

In the questions after the lecture, Mr Wells revealed his theory about why Leonardo studied anatomy in such detail. Leonardo was a natural philosopher and this meant he always wanted to understand the relationship between structure and function in nature. In addition he was unencumbered by traditional theories and could use his incredible observational and artistic skills. Although Leonardo had a poor opinion of contemporary Italian physicians, if his scientific work had been published he would clearly have had a great influence on the development of medical science.

The morning after the lecture I gave Mr Wells and his wife Lada a short medical history tour of Lancaster. We swapped stories about castles; I told him about the Lancaster castle surgeons and how a young Richard Owen had become so interested in phrenology that he had stolen a head from the castle. He told me about his first visit to the archive at Windsor Castle to view the Leonardo drawings. The archivist said they had 40000 works by the grand masters and that there were an equal number of Michelangelo anatomical sketches in the collection as well!

Further reading:

The Heart of Leonardo. Francis. C. Wells. Springer 2013. Leonardo da Vinci The flights of the mind. Charles Nicholl. Penguin 2004. 